\title{
On the Obstacles and Strategies in English Listening Teaching*
}

\author{
Xiaoling Yang \\ Foreign Language School, Nanchang Normal University, China
}

\begin{abstract}
Listening comprehension can be affected positively or negatively by various factors. The factors can be identified as internal and external. They are analyzed respectively and several effective strategies are also presented afterward. The barriers to listening are those of language knowledge, listening habits, psychological quality, cultural background and so on. The strategies should be as follows: training students' listening skills and good habits, laying stress on training psychological quality, broadening the cultural background knowledge, breeding interest on listening, using student-centered teaching method, ect. Due to the disagreements with previous teaching approaches over the past years, listening teaching, step by step, pays heel to the employment of listening strategies and the listening strategies production.
\end{abstract}

Index Terms —obstacles, listening, strategies, listening teaching

\section{INTRODUCTION}

Listening, just as its name implies, is to understand what you hear. With an increase of intercultural communication, English is taking greater and greater effect in transmitting messages and expressing oneself. In the five English skills such as listening, speaking, reading, writing and translating, listening has its priority (Johnson, 2002). For example, a child first listens for a long time before he is able to speak. It is the same for an adult who learns English as a foreign language. So listening plays the first and the most important role in learning a foreign language. But in the practice of English teaching in China, it doesn't succeed in getting as much attention as reading, writing and translating in China. Most teachers do in class is only to play the recorder and check answers to exercises. Therefore, most students can rarely study anything in class, and they thank it is difficult to understand what they listen. That is to say, how to make use of advantaged condition to improve ability of listening is an urgent problem we must solve. This thesis analyses factors affecting English listening and proposes several effective strategies to help students improve their listening.

\section{OBSTACLES IN LISTENING COMPREHENSION}

Listening comprehension is both a technique and a capability, which is a rather significant in second language study (Rost, 2000, p12-27). According to it, the degree of listening capability straight pose great influence on other language techniques. Thus, obstacles affecting listening comprehension should be studied.

\section{A. Internal Factors Affecting Listening Comprehension}

There are several internal factors which influence the quality of listening comprehension.

1. The English sounds and sound patterns

In accordance to an American scholar, Rita Wong, phonetics is typical in listening comprehension. The reason is that sound is the direct way of listening and speaking. We can express ourselves correctly only pronouncing well. But in the course of study of English phonetics, there are considerable part of the students for a long time by the influence of the native language and local dialect, in addition, the middle school stage does not take the seriously pronunciation study, as well as the wrong pronunciation study habits, have formed the non-standard, and even wrong English pronunciation. Even those students whose pronunciation is basically accurate, in a real communication, have difficulty forming a fluent flow of language. This is because in continual expression, the mutual influence between different words and between syllables. So there occurs some changes on the pronunciation, such as assimilation, elision, loss of explosion, etc, which will undoubtedly result in the difficulty on distinguishing sounds for those non-standard listeners. In listening, most of the student cannot distinguish these phonemes clearly: /i:/ /i / , /w / /v / , / / / / / . Thus, when they hear: sit, they understand it as : seat ; when they hear: vest, they understand it as : west; when they hear : light, they understand it as : right or night. In addition, many students tend to pronounce a word with diphthong /ai / as a word with /y/ (Underwood, 1989). These are easy to make mistakes in such listening examinations: make an identification which one is pronounced in the following pairs: bike, back and: fight, fat. And students also find it difficult to obtain the real meaning owing to different tones and intonations.

\footnotetext{
* This paper is funded by 11531 project of Nanchang Normal University
} 


\section{Vocabulary}

Students lack sufficient vocabulary supposing compared with the numerable listening materials saving daily scientific, social, cultural, economical life. When they first encounter a unknown word, they feel afraid. The second new word makes them perplexed. And the following vocabulary always cause them to abandon. And they are blocked by some useful phrases and idioms in listening.

For instance: W: How did Mary do on her English exam?

M: She passed with flying colors.

Q: What does the man say about Mary?

A: She has already taken the exam.

B: She did very well on the exam.

C: She managed to pass the exam.

D: She fainted during the exam.

If you don't know what's meaning of the idiom" pass with flying colors", you can't chose the right answer is B. Moreover, " what are eating you? " (What is wrong with you). Not knowing that idiom, students will not understand “cry over spilled milk” (为过去的失败而懊悔), “It is Greek to me” (我一倥不通). If students don't understand that, they will not succeed in understanding their listening.

3. Lexicology and grammar barriers

Over the procession of listening comprehension, students could not finish the exercises of sound recognition, or master the language continuity. Provided new vocabulary appears while they're listening, it is difficult for students to understand the whole meaning, even some students do not continue and spend some time thinking about the new vocabulary that they encountered before when listening are going on. It is the case for grammar. Grammar is the "skeleton" of English, without which, English is a heap of "flesh" which cannot stand up in the right order. Grammar can aid students to seize the implication of the vocabulary, and understand them accurately, which is essential to comprehend the condition of a whole text. It gives students a base for judging the time of the action happening, the person of the operator or supporter. What is the obvious evidence? Whether is it the subjunctive mood? etc. If students are not good at grammar, it'll influence their marks directly as they are listening.

For example: "But what happens if it rains? What are we going to do then?"_-We'll have to count on good weather. But if it does rain the whole thing will have to be canceled." In this sentence "“count on"means"depend on",and "the whole thing will have to be canceled"is about the future of the virtual hypothesis, if the students lack of grammar knowledge, they will not grasp the real meaning of the subjunctive mood, the content will sound more difficult to understand.

4. Listening customs barriers

The aim of listening is understanding the main idea of the passage. Over the procession of listening, students should try their best to seize the major content, which is very important (Vandergrift, 2016, p154-166). But many Chinese students don't form some good habits when they are listening. For example, they always try their utmost to understand meaning of every word, every sentence, as they catch a new vocabulary or a difficult sentence, they abandon and it is no doubt that they have no ability to understand what they hear. While some students can't think in English, but in Chinese, that is to say, they are listening, translating in English. Those bad customs, from some ways, are the key elements which affect their listening comprehension. Notice to train their listening skills and good habits. It is, in fact, needless to understand every vocabulary, every sentence. It is enough to catch main points, and understand the main idea. Supposing you pay more attention on 'a Heart Translation' when you are listening or listening to English, reflecting Chinese, invisibly adds to your mind a middle link, that's why your tempo is slow, you are behind the speed, and that's the reason why you lack time to pay heed to the main idea, let alone grasp the implication in it.

\section{B. External Factors Affecting Listening Comprehension}

Finishing the internal factors, it is of necessity to describe External factors affecting listening comprehension.

1. Psychological quality

Serious and formal teaching is usually a barrier for students to communicate freely. Linguists tell us that it is easy for students to produce fright when they are at their nervousness for they are afraid of being questioned by the teacher. Sometimes students feel too nervous to concentrate on what they are listening. Sometimes students encounter some unknown words or difficult sentences, they'll feel the frights. Even some students are frightened when they begin to listen. Such kind of state will make students' failure in listening.

Some students are from the village, and they seldom have chances to listen to the tape. Their lack of experience also leads to them confused. Before listening, knowing nothing about the information of the listening materials, they feel anxious and worried. It seems that they are just like those who are facing customs' officers not knowing how to express themselves. Such kind of state often leads to students passive in listening.

Students are divided into several types in accordance with their abnormal psychological quality: they attach much importance to facial action; they have anxiety of trait and environment; they don't obtain same psychology. Such students don't succeed in listening well owing to their unhealthy psychology.

2. Teachers 
Injection in the traditional teaching, teachers were overwhelmingly dominant in the spoon-feeding education, resulting in the student passive acceptance, apathy, lack in initiative and creativity of the negative effects. With the deepening of the reform of teaching, the students' dominant position in teaching has been paid more and more attention, especially in college English teaching. Heuristic, I heard that style, communication style, and other advanced, innovative teaching methods are increasingly widely used. Respect for the individual, emphasizing the ability to obtain teaching ideas is more fully reflected, students are increasingly comprehensive initiative to play, it is very gratifying and trends.

3. Cultural background

The background or prior knowledge can affect listening comprehension. Different countries have different cultural backgrounds. Such as history, culture, customs and habits, even life styles. If students know little about these kinds of knowledge, they cannot have a good understanding of speakers even though they are familiar with the heard word. For example, if we give two pieces of passage for student to listen, one is introducing 'Chinese Spring Festival', the other is English 'Christmas'. I'm sure it is very easy for students to understand Spring Festival, in that it is traditional in our country, everyone knows it well, which is helpful for them to understand. While students will get a good opinion about what is occurring at all, only when teachers explain Christmas tree, Santa Claus and Christmas gifts (Weinstein, 2014, p315-327).

For example, in one of the listening material on American family, it is said that: Jack's mother led Jack to Hollywood to travel the day before Christmas Day. And then the question is: When did they leave for Hollywood? If the students do not know which day the Christmas Day is, it is difficult to answer this question.

Conflicts or shock of culture will happen assuming students do not master much about cultural background. For example an article about American telephone network articles have phrase:" It provides 800 telephone service." In the U.S., makes the long-distance telephone call which does not collect fees must dial the number 800 .

If you don't understand this point, you will understand the correct means of this sentence "the nets provide 800 no fee telephone service" as "the net provides 800 call services".

4. Interest in English listening

Interest in learning is also called interest in cognition or thirst for knowledge. It is the most practical and the most active component part in learning motivation. It is an intentional activity with moody coloring which strives to recognize the world, eager to get culture-science knowledge and explores the truth continuously. In teaching learning, motivation in learning and interest in learning are the most directly factors which affect learning consciousness and enthusiasm. It is well-known that: "interest is the best teacher". Whether students learn well or not has direct relationship with interest in learning.

All mentioned above are barriers in listening comprehension and how to remove barriers which are another question.

\section{StRAtegies IN TEACHING Listening}

With the deep research of obstacles to listening ability, it is in that teachers think it is merely to exam the learners' listening capability and needn't teach any approaches and techniques.

\section{A. Discriminating among the Distinctive Sounds of English}

Listening helps students to recognize differences between sounds. For instance, in some vowels, such as /i://i//e/ , also in such consonants as $/ \mathrm{k} / \mathrm{g} / / \mathrm{v} /$. we must help them through practice so that they are subtle to the wideness of the open teeth, the form of the lips, and the strain of tongue and larynx, and capable of noticing the difference between /g/ and /k/ , and /i:/ and /i/ as in the words pig and pick, ship and sheep; sun and run, etc. we must point out that in each pair, a difference in a single sound ( phoneme) makes a new word with an entirely different meaning.

\section{B. Enlarge Vocabulary}

Vocabulary is the basis of language. In order to improve listening, listeners must have enough vocabulary because vocabulary influences listening directly. However, reading is the only way to increase vocabulary, deepen comprehension. As for the familiar words, we usually know the spelling and pronunciation; while it is difficult to comprehend the meaning of the unfamiliar words. In the course of listening, one sentence may not be understood clearly owing to one or two strange words. Thus we know listening is restricted and closely connected with vocabulary. In order to improve listening thoroughly, we must consider how to increase vocabulary. When we read an article, we often meet some unfamiliar words or phrases, which require us to look up their meanings in the dictionary. We can increase our vocabulary by means of this. Besides, consulting the dictionary can deepen the comprehension of words, set phrases, and special meanings.

In general, listening and reading supplement each other. Apart from the major, we should contact other subjects so as to improve listening comprehension. (Wang, 2007, p172-174)

\section{Focus on Improving Grammar}

Mastery of grammar, to improve their English listening ability is also an important aspect, in the listening process, when faced long sentences difficult sentences, if we can use knowledge of grammar, good sentence element analysis to 
find the topic sentence, key words, clearly identify the master and slave sentence or other modifiers, you can accurately understand the whole sentence meaning.

\section{Notice to Train Their Listening Skills and Good Habits}

So-called listening skills here, include skills on phonetics and the comprehension skill on it. The phonetic skills refer to the terms as sound-linking, weak form, sentence stress, sense - group etc. Comprehension skills refer to the index, calculation, and choice of content, etc. Besides, students should have a fast reading before any listening begins, attempt to find some information in advance. Namely, they should look through the exercises extremely fast, seize any probable hint of them, memorize them for a short time, then take notes while they are listening, reinforce their memory. When you write down the notes you should also catch the major points. For example, using Arabic numerals to take down the numerals, using code name instead of places, person's name, ect. If the words are very long, you can use abbreviation, and if the sentence is long enough, you can get the chief component. While listening to questions and answers, you can connect the main point of information to the question organically, while you are listening to a conversation or a short passage, you should grasp the main idea, top sentences. To careful to avoid trying to catch one or two new words, influenced understanding the whole passage. At the same time, bad habits should be got rid of. For example, in order to catch the meaning of every top sentence at every paragraph, according to their grammatical units we'd train students' ability to summarize, seize the chief point, think in English way, break away from the influence of our native language - Chinese.

\section{E. Laying Stress on Training Psychological Quality}

It is undoubted that psychological quality is quite important to do everything, so dose listening comprehension. It is very typical that students develop a good condition while they are listening. Students should know that listening is the first pace to learn language, they should pay heed to learn it excellent at the very start. At the same time, students should also know that it is true listening is very difficult, not only for some of them, but for every Chinese student. So there is a need for teachers to encourage students to set up confidence, enhance spirits to overcome difficulties. Meanwhile they should also see that so long as you have a persistent in it, you'll certainly be good at it later and never to be afraid of it.

\section{F. Student-centered Teaching Methodology}

Teachers should change the traditional model of "Listen - check the answer - listen again", and instead of the modern model of "the student-centered" in the listening ability of students, let them do some role-play the appropriate level, consistency and repeat, etc. listening materials related activities.

\section{G. Broadening the Cultural Background Knowledge}

To achieve the cultural background knowledge is multi-channel, In foreign language teaching, the teachers should pay more attention to the introduction of culture and the cultivation of students' intercultural consciousness, under the class, students can read a lot of books about the English countries' social, historical and cultural knowledge. In listening process, the teacher as far as possible to teach students relevant cultural background knowledge, with some warm-up exercises to activate students' previous cultural background knowledge. On select the material of listening should be based on textbook, supplemented by other material. The choice is abundant in content, cover wide, such as politics, economy, military, culture, science and technology and other fields but not too over-specialized materials. Teachers should create more of the language environment, such as the second class that makes the students take full advantage of multi-media classrooms, multi-functional audio-visual and other modern media offer a wealth of resources. Wide range of interesting and effectiveness of the natural expression information easy to stimulate the students' interest, broaden the cultural background knowledge, and gradually improve their listening ability.

\section{H. Breeding Interest on Listening}

"Interest is the best teacher", for this reason, to cultivate interest plays a very important role in English listening. Two ways are worthy of being mentioned in cultivating students' interest in learning: One is to choose interesting listening material for them to listen to. The listening material should be interesting to the students. An interesting listening material can easily arouse students interested in learning. Once, the author let the students listen to an interesting story called: Shop-Lifter which was about how a female thief stole some cosmetics in a supermarket. The students were so interested in it that they understood this story easily. Apart from the textbook, the author often uses English songs as an auxiliary method to arouse students' interest in learning. Music is sound; students have ability not only to enjoy it, escape from the active classroom atmosphere, but study some points of language and culture in English-speaking countries. Also, listening to English songs can help students form habit in listening to English for there have lots of liaisons and imperfect plosives in each English song. Given students listen to English songs normally or now and then, they would get accustom to liaisons and imperfect plosives and so on. They conflict problems of this type once more in their listening class, they are able to tangle it skillfully.

The other is to express clearly the purpose of our listening, in another word, to give the evident goal to the students before they listen to the recording or tell them what kind of task we wound finish after listening. When students have clear purpose why they listen to a certain piece of paper or they are aware of that what kind of task they would finish 
after listening, they can have strong desire to listen. For example, in terms of a piece of narration, students can roughly know that what this passage is about by reading the exercises which are concerned to it. With such kind of rough knowledge on passage which the students would listen to, students would be eager to listen. Hence, it is necessary for the teacher to express the purpose which students listen to a topic and if necessary to explain the exercises connected with listening materials for the students before they listen to the recording because the relevant exercise is, to some degree, a clue to the listening material. The better students understand the exercises, the easier they can comprehend the recording.

\section{CONCLUSION}

Listening comprehension is a complicate, active procedure where students must distinguish between sounds, understand words and grammatical structures, explain stress and intonation, remember what was collected in all of the above, and interpret listening within the immediate and the greater sociocultural situation of the utterance. Students' ability of listening is based on whether he or she has mastered the relevant knowledge or techniques well or not. Through analysis of factors which affect English listening, we understand that there are many reasons why students feel it difficult to learn English listening, among which several factors have been analyzed: phonetic knowledge, vocabulary quantities, background knowledge and psychological factors, and so on. In addition, in order to solve these problems, some suggestions are put forward: do not forget to learn some relevant phonetic knowledge while we drill listening; enlarge vocabulary quantities as many as possible; learn some background knowledge on a large scale and overcome psychological factors in the process of listening. Except for these four aspects, there are still many factors affecting English listening. Teachers should put emphasis on training psychological quality, which is important to learn English well. In the past decades, teachers were the core of their class and they are in charge of class. However, the situation is changing, student-centered is becoming the center of class. In order to enhance students' listening level, teachers had better broaden the cultural background knowledge while teaching the skills of listening. Last but not the least, students' interest on listening might be cultivated. What has been suggested here is limited and merits further research.

\section{REFERENCES}

[1] Keith Johnson. (2002). An Introduction to Foreign Language Learning and Teaching. Beijing: Foreign Language Teaching and Research Press.

[2] Rost, M. (2000). Listening in Language Learning. London: Longman.

[3] Underwood, M. (1989). Teach Listening. England: Longman Group UK Limited.

[4] Vandergrift. L. (2016). Facilitating second language listening comprehension: acquiring successful strategies. ELT Journal.

[5] Weinstein, C. and Mayer, R. (2014). The teaching of learning strategies. Handbook of Research on Teaching, New York: Macmihan.

[6] Yinchun,Wang. (2007). Some Thought on Improvement of English Listening Instruction. High education and academic research.

Xiaoling Yang was born in Nanchang, China in 1970. She received her Master degree in linguistics from Donghua University of Technology, China in 2003.

She is professor in the School of Foreign Languages, Nanchang Normal University, Nanchang, China. Her research interests include English teaching and cross-culture. 